\title{
Preparing teachers to use educational games, virtual experiments, and interactive science simulations for engaging students in the practices of science
}

\author{
Christian Fischer and R. Charles Dershimer \\ University of Michigan, Ann Arbor, USA
}

\begin{abstract}
Given that reform-based instruction emphasizes inquiry-based learning geared towards science and engineering practices traditional science instruction might not be able to fully support students to achieve 21st century skills. Implementing digital technologies for learners might provide promising perspectives on how to effectively teach reform-based science. Emerged from a technology workshop for pre-service science teachers, this paper provides suggestions on how to integrate educational games, virtual experiments, and interactive science simulations in reform-based science instruction. Besides reflecting on affordances of these digital tools, practical recommendations for teaching preparation are given including (a) how to review educational games for instructional adoptions, (b) how to align existing curricula materials supplementary to interactive science simulations to reform-based teaching, and (c) how to develop standards-aligned instructional materials for virtual experiments.
\end{abstract}

\section{Introduction and Theory}

When schools are engaged in the adoption of new curricular standards teachers are often faced with additional external loads, besides their normal teaching practice. These include the use of new tools and teaching materials designed in response to the changing standards that intend to foster student learning. Current educational reforms in the United States, initiated through the National Research Council's Framework for K-12 Education (National Research Council, 2012) and the Next Generation Science Standards (NGSS) (NGSS Lead States, 2013), promote changes in science education emphasizing 'inquiry-based' instruction engaging students in science and engineering practices. While traditional forms of instruction might not be sufficient for effectively supporting teachers in their response to these curricular changes, digital technologies might provide one potential pathway for teachers to advance student learning and achievement (e.g., U.S. Department of Education, 2010, 2013). Design characteristics of technologies for learners include "support[ing] the needs, goals, and styles of individuals. [...] They are designed to be flexible, customizable, and adaptive to learner needs, and are best suited to fit learner-selected goals" (Halverson \& Shapiro, 2012, p. 3).

Although it is tempting to overestimate the potential of technologies for learners as an influence on student learning, materials and technology are necessary but not sufficient aspects of teachers' instructional capacity for how teachers work with students and content to reach their goals, as indicated in the instructional triangle (Cohen \& Ball, 1999). Technology-enhanced learning environments might have the potential of positively impacting teachers' reform-based science instruction to facilitate standards-based student learning. If teachers can learn how digital technologies for learners can act as content resources, how these tools can be accessed and integrated in lesson planning, and how they can be used to engage students in the practices of science in classroom instruction, then these tools can also support teachers with the adoption of changing curricular standards. A well planned implementation of digital technologies to engage leaners in reform-based science instruction can help teachers achieve their goals of engaging students in science and engineering practices. Potential benefits of integrating these technologies into the classroom include but are not limited to increased access to experiments that are often not realizable 
in traditional science instruction (because of either very cost-intense laboratory materials or not "visible" conceptual phenomena), immediate manipulation and observation of interactions between variables that allow students to focus on the conceptual knowledge embedded in scientific principles (instead of continuously enacting procedural knowledge intense activities such as drawing graphs), and individual feedback based on personalized student interactions with the learning environment around science and engineering practices that are often challenging to assess and support in real time, among many others (e.g., Gröber, Vetter, Eckert, \& Jodl, 2008; Joler \& Christodoulou, 2001; Moore, Chamberlain, Parson, \& Perkins, 2014).

Therefore, we designed a workshop on how digital technologies for learners can act as content resources, how to plan technology-enhanced instruction adopting reform-based science standards, and how to integrate these digital tools in reform-based science teaching.

\section{Concept and Implementation}

This technology workshop was implemented in the Teaching Secondary School Science course for pre-service science teaching interns at the University of Michigan, a large public research university in the Midwest of the United States. In total, 18 pre-service science teaching inters participated in this three-hour workshop. The group of teaching interns was diverse with respect to the school placements for their teaching internships, the respective science disciplines in which they are being certified, and their content knowledge for teaching (Ball, Thames, \& Phelps, 2008).

When attempting to use digital technologies for learners in science classrooms, teachers need to make numerous decisions while they are planning their instruction. A major question for the pre-service science teaching interns was how to ensure that the technology use is aligned to the lesson's instructional goals and also supports the intended learning. Therefore, it became important for the pre-service science teaching interns to learn how to select resources and adopt them towards individual lesson objectives around science content and practices.

Hence, goals of the workshop were two-fold:

1. Exposing pre-service science teaching inters to a variety of digital technologies and discussing implementation affordances in reform-based science instruction.

2. Introducing a framework to provide a scaffolding of technology adoption teaching practices for effective lesson planning with digital technologies for learners.

The digital technologies for learners presented in this workshop were educational games from BrainPOP's GameUp collection (BrainPOP, n.d.), interactive science simulations from the Physics Education Technology project at the University of Colorado Boulder (University of Colorado, n.d.), and virtual experiments from the Remotely Controlled Laboratory project at the Ludwig Maximilian University of Munich in Germany (Girwidz, Pickl, \& Krug, n.d.). The pre-service science teaching inters actively explored each tool through technology adoption teaching practice scaffolds which included strategies for selecting appropriate tools based on teaching objective, aligning and augmenting existing instructional materials towards teaching objectives, and designing new instructional materials based on teaching objectives.

\subsection{Educational Games}

Combining the motivational character of games with elements of instruction can be viewed as a promising direction in educational research in order to enhance students' motivation for 
learning. "Good" games have several inherent characteristics that are similar to good learning environments. For example, Gee (2005) describes principles of "good" game-based learning environments in the categories of empowering learners, problem solving, and understanding. Learners can be empowered if they are supported (a) to actively co-design their learning experiences; (b) to customize their learning based on own decision-making regarding learning paths; (c) to engage in identity building processes; and (d) to use tools and technologies that foster manipulations of real world phenomena and enhance knowledge building processes (Gee, 2005). Problem solving is fostered through (a) a wellchosen order of the problems learners face in early learning stages; (b) productive failure; (c) repeated practice and cycles of expertise; (d) information that is available both just-intime and on-demand; (e) a simplification of systems emphasizing key characteristics of otherwise overwhelmingly complex systems; (f) sandboxes that encourage explorations without risks of failure; and (g) practices situated in meaningful contexts (Gee, 2005). Understanding is facilitated through (a) a "bird's-eye view" on how near learning goals fit into the complex structures of the overall learning goals and (b) meaning-making processes that actively reconstruct prior learning experiences (Gee, 2005).

These principles of game-based learning environments can be viewed as "gameplay/engagement" characteristics. Although educational games might incorporate several of these gameplay/ engagement characteristics, in order to facilitate digital gamebased learning, the game must also support standards-based learning. An educational game design classification pattern, as described in figure 1, can be thought of as a two-by-two matrix that slightly modifies Prensky's (2006) classification of game-based learning.

\begin{tabular}{c|c|c|}
\cline { 2 - 3 } \multicolumn{1}{c|}{$\begin{array}{c}\text { high } \\
\text { Engagement } \\
\text { low }\end{array}$} & $\begin{array}{l}\text { Pure games / } \\
\text { "Gamification" }\end{array}$ & $\begin{array}{l}\text { Digital game- } \\
\text { based learning }\end{array}$ \\
\cline { 2 - 3 } & $\begin{array}{l}\text { "E-learning"/ } \\
\text { Computer- } \\
\text { based training }\end{array}$ & $\begin{array}{l}\text { "Spinach-sundae } \\
\text { games" }\end{array}$ \\
\hline & lowigh \\
Standards-based Learning
\end{tabular}

Figure 1: Game design classification matrix, slightly modified from Prensky (2006).

Unsurprisingly, some criteria that evaluate gameplay/engagement and standards-based learning might overlap. Games that have a high 'gameplay' factor but are low in relation to standards-based learning exemplify gamification (e.g., Deterding, Dixon, Khaled, \& Nacke, 2011) in that they are engaging for students but lack of support for students to engage with the teacher's specific content objectives. Games that are low in gameplay/engagement, but high in standards-based learning can be thought of as "spinach-sundae" (Jenkins as cited in LoPiccolo, 2004). In this case, the game, like a sundae, may include engaging characteristics, and the content being standards-based is healthy like spinach. However, when combined, teachers might find that, just like a spinach-sundae, after the initial interest the students do not complete the game, and if they do, students certainly do not want a second helping. On the other hand, if a game has a design that makes use of many of the gameplay/engagement features, while also engaging students in robust standards-based learning of content, teachers can plan on these games being motivating to students while also useful for meeting their planned goals for instruction. 
One example of an online platform that hosts educational games usable in $\mathrm{K}-12$ settings in a variety of subjects including science, mathematics, engineering, social studies, and English, among others is BrainPOP's GameUP collection (https://www.brainpop.com/games). All games are free of charge and accessible through any web browser. Accompanying most educational games, content-related animated videos are offered using a subscription business model. Supplementary lesson plans and other instructional materials are provided on BrainPOP's online platform for educators (https://educators.brainpop.com). However, the instructional materials are organized by topics and focus on the broader content-related goals instead of providing exemplary activities that integrate specific educational games in classroom instruction.

Technology adoption teaching practice 1: Evaluating and selecting tools for instructional adoption

With an increased number of educational games available for every content area, it becomes important for teachers to select digital technologies for learners that are suited to support their instructional objectives. Therefore, this workshop modeled the technology adoption teaching practice of evaluating educational games with respect to their potential to continuously engage students in the activities while enhancing student learning based on accurate, significant, and worthwhile content. To evaluate the gameplay/engagement dimensions, Gee's (2005) principles of "good" game-based learning environments were used. To address whether the integration of gameplay/engagement characteristics with the content is addressed, the workshop modeled criterion-based game review processes using the following three prompts:

\section{1) Learning engagement}

How are learners motivated throughout the game?

2) Learning design and content integration

Are scientific ideas represented correctly? How does the game facilitate learning of content and science and engineering practices? What additional guidance do teachers need to provide?

3) Learning assessment

How did the game monitor and evaluate learning? How can teachers assess students' learning?

After the review of different educational games from BrainPOP's GameUp collection, a coached discussion was held and recorded on whiteboards to review ideas that were generated in relation to the three prompts. In addition, the pre-service science teaching interns were asked to reflect on affordances and challenges of educational games. For instance, Sarah ${ }^{1}$, a Chemistry pre-service teaching intern, conjectured that she intends to use educational games because "[...] games are engaging and exciting, and can support learning if used correctly [...]." Similarly, Cheng, a Biology pre-service teaching intern, stated that "games are fun and it starts them [students] thinking about strategy [...]."

\subsection{Interactive Science Simulations}

Interactive science simulations are tools that provide visualizations of scientific phenomena. Students can explore multiple representations and real world connection through interactive interfaces that allow dynamic feedback. Interactive science simulations have the potential to engage students in explorations that might lead to conceptual understanding, ownership experiences of the learning processes and to give students appreciation of the

1 Note: Student names have been changed. 
sciences as accessible and enjoyable disciplines (e.g., Moore et al., 2014; Podolefsky, Perkins, \& Adams, 2010).

The Physics Education Technology (PhET) project at the University of Colorado Boulder is a prime example for interactive science simulations (e.g., Perkins et al., 2006). PhET provides interactive science simulations in science and mathematics with content ranging from elementary school through introductory college courses on its online platform (https://phet.colorado.edu). The interactive science simulations are free of charge and accessible through any web browser or a PhET-developed offline program. Supplementary instructional materials are available for each PhET interactive science simulation within the PhET infrastructure. Some of these teaching resources are developed by researchers at UC Boulder, others were submitted by teachers or other educators.

Technology adoption teaching practice 2: Aligning and augmenting existing materials to support tool implementation

Teachers frequently encounter fully developed third-party lesson plans, curricula, teaching recommendations, worksheets, and other instructional materials supplementary to digital technologies for learners which are related to a class they are teaching. However, since they did not design these materials on their own, these materials might not be perfectly aligned with their instructional goals and their specific class and school context. Therefore, teachers need to master the important skill of transforming existing instructional materials into materials that are aligned to standards-based science teaching. In the technology workshop, pre-service science teaching interns were adopting instructional materials developed for the Beer's Law Lab simulation (https://phet.colorado.edu/en/simulation/beers-law-lab). This interactive science simulation is targeted towards high school students. For instance, students can explore relations between the wavelength of transmitted light, the path length through a solution, the solution concentration, and the transmittance and absorbance coefficients (Moore et al., 2014). As part of the workshop, the pre-service science teaching interns reviewed an instructional activity called Colored Solutions and Spectrophotometers (Chamberlain \& Hendrickson, 2013). Prompts for modifying the existing instructional activity towards better alignment with the Claim-Evidence-Reasoning framework (McNeill \& Krajcik, 2012) included the following:

1) Review the student worksheet for a laboratory session on colored solutions and spectrophotometers regarding connections to the Claim-Evidence-Reasoning framework?

2) How could the student worksheet be modified for a better fit with the ClaimEvidence-Reasoning framework?

3) Based on your experience working with this PhET simulation, what advantages and challenges might the use of interactive science simulations bring to your classroom?

After sharing ideas for improving existing teaching materials, the pre-service science teaching interns reflected on potential usage of interactive simulations in their own future teaching. For instance, Hope, a Biology pre-service teaching intern, expected to use interactive science simulations because "students can do a variety of activities with these simulations, such as collaborate with other students, use predict-observe-explain, or a CER [Claim-Evidence-Reasoning] to demonstrate their preconceptions and the knoweldge [sic] they develop." Additionally, Lindsey a Physics pre-service teaching intern, described that interactive simulations "[...] allow students to connect theory and content to real time phenomena." 


\subsection{Virtual Experiments}

Virtual experiments are real experiments that can be remotely controlled with a computer with any web browser. Real laboratory experiments are connected through an interface with a webserver. The manipulation of variables on the real experiment is directly observable on the computer screen through web cameras. Some virtual experiments have built-in data collection system that allow immediate electronic data analysis (e.g., Jia et al., 2006). The integration of virtual experiments in reform-based science instruction allows an interactive use of experimental laboratory set-ups that include digital hands-on experience with authentic science materials (e.g., Gröber, Vetter, Eckert, \& Jodl, 2007; Gröber et al., 2008). The Remotely Controlled Laboratories (RCL) project at the Ludwig Maximilian University of Munich in Germany provides 13 different RCLs (http://rcl-munich.informatik.unibwmuenchen.de). The content of the RCLs is targeted towards high school Physics courses. Detailed supplementary materials are provided for each RCL including a description of the experimental set-up, the content background, an analysis of the results of the experiment, and teaching materials such as sample tasks, worksheets, and discussion questions.

\section{Technology adoption teaching practice 3: Developing instructional materials to support tool implementation \\ Teachers who intend to implement digital technologies for learners in their instruction that does not provide supplementary instructional materials (or that only provide inadequate supplementary instructional materials which cannot be easily modified towards teachers instructional goals, applying technology adoption teaching practice 2) need to develop appropriate instructional materials on their own. In this workshop, the pre-service science teaching interns were asked to develop an outline of an instructional activity for pre-selected virtual experiments of the LMU Munich's RCL project. The following guiding questions were used for planning the instructional activity:}

1) What variables could be measured? What are dependent/independent variables?

2) What potential hypotheses could be generated?

3) How could a data collection and data analysis process look like?

4) What state standards or performance expectations of the Next Generation Science Standard could an activity with this virtual environment be related to?

Similarly to prior parts of the workshop, a moderated discussion took place presenting instructional ideas for activities with each virtual experiment while attending to the four guiding questions. Afterwards, the pre-service science teaching interns were asked to reflect on their potential use of virtual experiments in their future instruction. For instance, Joe, a Physics pre-service teaching intern, predicted to use virtual experiments in his instruction "[...] because they are a good way to get students engaged in experiments that may not be possible in a classroom setting." Similarly, Eryn, a Biology pre-service teaching intern, hypothesized to use virtual experiments "[...] because they allow students to work with phenomena and principles that they would never get to otherwise."

\section{Discussion and Recommendations}

Digital technologies for leaners have the potential to both support reform-based instruction and facilitate student learning in the sciences. All described technologies have the potential to support teachers with reform-based science instruction that emphasizes inquiry-based instruction towards science and engineering practices. However, implementations of digital technologies for learners in classroom instruction must be mindful and aligned to teachers' instructional goals. 
This workshop offers initial insights on a potential pathway to not only expose teachers to digital technologies for learners but also to support teachers with meaningful technology integration in their science instruction through three technology adoption teaching practices. The presented scaffold illustrated how to select digital technologies for learners based on a list of evaluation criteria, how to align and augment pre-existing instructional materials supplementary to digital tools towards specific teaching situations, and how to develop new instructional materials that support technology integration. In relation to the workshop goals, most pre-service science teaching interns indicated the benefits of the provided technology adoption teaching practices scaffold for teaching preparation, especially with respect to justifications of the integration of digital technologies in reformbased science teaching based on how to meet instructional goals. Reviewing reflections on affordances and challenges for technology integration, the pre-service science teaching interns indicated an overall strong inclination to implement digital technologies in their own future teaching. Additionally, their reflections regarding potential benefits of technology integration in science teaching were similar across the three different types of digital technologies for learners, especially emphasizing the benefits of enabling all students to explore phenomena and principles with experiments, which might not always be realizable in traditional science instruction either due to the costs of individual experimental set-ups or due to the nature of the specific phenomena.

Therefore, recommendations for providing support to prospective and current teachers that might enable successful technology integration in reform-based science teaching include the following:

- Exposure to a broad variety of digital technologies for learners

- Scaffolded support with technology adoption teaching practices for meaningful implementations of digital technologies for learners in individual teaching contexts

- Opportunities to reflect on technology use with respect to teaching goals

Given the potential of digital technologies for learners to deeply enrich reform-based science instruction geared towards 21st century teaching and learning, the importance of continuing the explorations of settings that effectively support educational stakeholders with technology integration in science classrooms remains high.

\section{References}

Ball, D. L., Thames, M. H., \& Phelps, G. (2008). Content knowledge for teaching: What makes it special? Journal of Teacher Education, 59(5), 389-407. http://doi.org/10.1177/0022487108324554

BrainPOP. (n.d.). BrainPOP. GameUp. Retrieved May 28, 2015, from https://www.brainpop.com/games/

Chamberlain, J. M., \& Hendrickson, S. (2013). Colored solutions and spectrophotometers. Retrieved from http://phet.colorado.edu/files/activities/3659/Beers_Law_Investigation.docx

Cohen, D. K., \& Ball, D. L. (1999). Instruction, capacity, and improvement (CPRE Research Report Series No. RR-43). Philadelphia, PA: University of Pennsylvania, Consortium for Policy Research in Education.

Deterding, S., Dixon, D., Khaled, R., \& Nacke, L. (2011). From game design elements to gamefulness: defining gamification. In Proceedings of the 15th International Academic MindTrek Conference: Envisioning Future Media Environments (pp. 9-15). ACM. Retrieved from http://dl.acm.org/citation.cfm?id=2181040

Gee, J. P. (2005). Learning by design: Good video games as learning machines. E-Learning and Digital Media, 2(1), 5-16.

Girwidz, R., Pickl, S., \& Krug, T. (n.d.). Remotely Controlled Laboratories. Front page. Retrieved May 28, 2015, from http://rcl-munich.informatik.unibw-muenchen.de/

Gröber, S., Vetter, M., Eckert, B., \& Jodl, H.-J. (2007). Experimenting from a distance - Remotely controlled laboratory (RCL). European Journal of Physics, 28(3), 127-141.

Gröber, S., Vetter, M., Eckert, B., \& Jodl, H.-J. (2008). Remotely controlled laboratories: Aims, examples, and experience. American Journal of Physics, 76(4), 374-378. 
Halverson, R., \& Shapiro, R. B. (2012). Technologies for education and technologies for learners: How information technologies are (and should be) changing schools. Retrieved from http://website.education.wisc.edu/halverson/wp-content/uploads/2012/12/021712-Tech-foreducation-and-learners-copy.pdf

Jia, R., Xu, S., Gao, S., Aziz, E.-S., Esche, S., \& Chassapis, C. (2006). A virtual laboratory on fluid mechanics. In Conference Proceedings of the 2006 Annual Conference of the American Society for Engineering Education. Chicago, IL. Retrieved from http://www.researchgate.net/profile/Elsayed_Aziz/publication/273771766_A_virtual_laborator y_on_fluid_mechanics/links/550c437a0cf212874160ae7b.pdf

Joler, M., \& Christodoulou, C. G. (2001). Virtual laboratory instruments and simulations remotely controlled via the Internet. In Antennas and Propagation Society International Symposium, 2001. IEEE (pp. 388-391). IEEE. Retrieved from http://ieeexplore.ieee.org/xpls/abs_all.jsp?arnumber=958873

LoPiccolo, P. (2004). That's edutainment! Computer Graphics World, 27(1), 4.

McNeill, K. L., \& Krajcik, J. S. (2012). Framework for constructing scientific explanations. In Supporting grade 5-8 students in constructing explanations in science: The claim, evidence, and reasoning framework for talk and writing. Boston, MA: Pearson.

Moore, E. B., Chamberlain, J. M., Parson, R., \& Perkins, K. K. (2014). PhET interactive simulations: Transformative tools for teaching chemistry. Journal of Chemical Education, 91(8), 1191-1197. http://doi.org/10.1021/ed4005084

National Research Council. (2012). A framework for K-12 science education: Practices, crosscutting concepts, and core ideas. Washington, DC: National Academies Press.

NGSS Lead States. (2013). Next generation science standards: For states, by states. Washington, DC: Achieve, Inc. On behalf of the twenty-six states and partners that collaborated on the NGSS.

Perkins, K., Adams, W., Dubson, M., Finkelstein, N., Reid, S., Wieman, C., \& LeMaster, R. (2006). PhET: Interactive simulations for teaching and learning Physics. The Physics Teacher, 44(1), 18-23. http://doi.org/10.1119/1.2150754

Podolefsky, N. S., Perkins, K. K., \& Adams, W. K. (2010). Factors promoting engaged exploration with computer simulations. Physical Review Special Topics - Physics Education Research, 6(2). http://doi.org/10.1103/PhysRevSTPER.6.020117

Prensky, M. (2006). Computer games and learning: Digital game-based learning. In J. Raessens \& J. Goldstein (Eds.), Handbook of computer game study (pp. 97-122). Cambridge, MA: The MIT Press.

University of Colorado. (n.d.). PhET interactive simulations for science and math. Front page. Retrieved May 28, 2015, from http://phet.colorado.edu/

U.S. Department of Education. (2010). Transforming American education: Learning powered by technology. Washington, DC: U.S. Department of Education.

U.S. Department of Education. (2013). Expanding evidence approaches for learning in a digital world. Washington, DC. 